\title{
An investigation into the undergraduate dissertation tutorial as a Personal Development Planning (PDP) process to support learner development
}

\author{
Dr Andrea Raiker \\ University of Bedfordshire, UK
}

\begin{abstract}
The investigation discussed in this paper was motivated by a finding revealed through analysis of the dissertation grades of final year undergraduates on an education honours degree. A third of dissertations received grades equating to third class honours or fails and this was viewed by the Faculty as being unacceptable. As a Fellow of the University's Centre for Excellence in Teaching and Learning with a focus on personal development, I was asked by the course leader to identify possible causes and suggest changes. My critical reflection on the dissertation suggested that its creation is predicated upon Personal Development Planning (PDP) processes practised through the mediation of the tutorial. I am investigating the effectiveness of the tutorial to support learner development over a two year period, contributing to an overarching action research project undertaken by the National Action Research Network (NARN). This paper presents the outcomes of the first cycle of my action research, involving the collection and analysis of quantitative and qualitative data from students and dissertation supervisors. At this stage it appears that the design of the dissertation meets the needs of some students but not all, particularly the lower third of the sample cohort. Furthermore some students, including a number of thirds and fails, do not perceive tutorial support as essential for the successful completion of their dissertations. Overall, it appears that the tutorial process requires review in order to support the autonomous and/or collaborative learning needed for effective learner development.
\end{abstract}

Keywords: action research; learner development; PDP; tutorial; dissertation. 


\section{Introduction}

Over the last decade various conceptions of Personal Development Planning (PDP) have been discussed in the literature (QAA, 2001; Brennan and Shah, 2003; Clegg and Bradley, 2006; Bush and Bissell, 2008). In general, this debate has had a dual focus: PDP as product (the Progress File); and PDP as a process (Buckley, 2007). Various practical applications have arisen from this debate on how students' academic studies should contain preparation for employment and the form this should take (Atlay, 2007). Atlay et al.'s (2009, p.1) perception of PDP as being '... a process embedded within the curriculum [that] should support students in facing these challenges and improving their skills' in both academic and work-related spheres resonates with the Higher Education Academy's definition: ' ... a structured and supported process undertaken by an individual to reflect upon their own learning, performance and or achievement and to plan for their personal, educational and career development' (2009, p.1). Both definitions can be applied to the purpose of the tutorial in the production of undergraduate dissertations. They confirm this research's aims of identifying the 'challenges' and 'skills' related to students' difficulties with their final assignments in which syntheses of their prior learning is presented prior to employment.

The range of problems experienced by undergraduates in completing their dissertations has been substantially documented. For example, Harrison and Whalley $(2006$, p.18) state that 'students have difficulty with time management, the enormity of the exercise, balancing dissertation work with other studies, self motivation and knowing what is expected'. From a differing perspective, Hammick and Acker (1998) suggest a key determinant affecting interaction between supervisors and students is their differing concepts of knowledge and power. Rowley and Slack (2006) emphasise the need for increased professional development for supervisors. They debate students' needs to understand the importance of the dissertation to their learning, and see this as a fundamental aspect of the supervisory role. Areas of potential difficulty are argued to be students' management of theory-practice relationships, effective access/evaluation of online resources, and understanding of research methodologies and design. Another perspective provided by Stefani et al. (1997, p.271) focuses on the divergence of supervisor and student perceptions about issues surrounding the dissertation. They suggest that, to increase the learning that students gain from the dissertation process, '...a climate of open dialogue... to share learning conceptions and to ensure that the 
assessment of any learning task is commensurate with the aims, objectives and learning outcomes' must be established. Socio-cultural theory (for example, that represented by Vygotsky, 1978) suggests that such a climate of collaboration is necessary to promote effective learner development.

Learning development is to be understood as a holistic concept, embracing conceptual change arising out of transformational experiences embedded in context and perceived from the learner's perspective. Transformational experiences occur when there is a paradigm shift from teaching to learning centrality (Biggs and Tang, 2007). Meyer and Land (2006) postulate that there are some aspects of learning that form portals, the passage through which provides access to landscapes of understanding critical for students' progress. The effect of these aspects is so profound that students' perceptions of their courses, their disciplines or even their world views are transformed. They argue that these learning landscapes are bounded but capable of expansion at any point or points on that boundary at any time depending on the stimulus. For Mezirow (1997), such transformations result in increased autonomy of the individual. For those who see students' self knowledge, understanding and problem-solving abilities as key to work and life (for example: Stefani et al., 2007; Kumar, 2008; Atlay et al., 2009), autonomy is a principal objective of PDP and hence learning development.

This investigation was stimulated through analysis of dissertation grades awarded to final year education undergraduates over the five year period ending August 2008. A growing tail of underachievement was identified with an increasing number of students not achieving expected grades in their dissertations. The production of a dissertation explicitly involves PDP processes leading to greater autonomy through the mediation of the tutorial. Students are supervised, not taught. Supervisors gradually cede control to the students so that they become increasingly autonomous through the structure of the tutorial system. The Bedfordshire approach to the tutorial system is to make five hours of one-to-one supervisory time available at the students' discretion. This can be face to face, or mediated electronically. Two research questions emerged from reflection on this underachievement and the autonomy required by the tutorial:

- How effective was the tutorial system as a PDP process leading to greater autonomy? 
- In which areas might PDP processes be developed to support the interface between the autonomous and collaborative learning required by the tutorial system?

This paper presents the outcomes of the first cycle of collection and analysis of quantitative and qualitative data. The second cycle, occurring at the time of writing, will involve the evaluation of PDP interventions to support students in their dissertation work arising from, and compared with, the findings of the first cycle. This project was conceived as contributing to a larger action research project undertaken by the National Action Research Network (NARN, 2007). NARN is researching and evaluating PDP and ePortfolio practice at 17 Higher Education Institutions (HEIs) in the UK. Therefore the approach of my contribution to this research was predetermined.

\section{Research design}

The approach of action research when applied to education is concerned with critical praxis, action informed by disciplined inquiry aimed at developing evidence-based knowledge and theory (Habermas, 1984; Elliott, 1991). It focuses on practical issues identified by practitioners as being problematic but capable of being changed (Eliott, 1991: Zuber-Skerritt, 1996). Action research involves '...changing individuals, on the one hand, and, on the other, the culture of the groups, institutions and societies to which they belong' (Kemmis and McTaggart, 1992, p.16). Furthermore, action research is '.... a form of collective self-reflective inquiry undertaken by participants in social situations in order to improve the rationality and justice of their own social or educational practices...' (Kemmis and McTaggart, 1992, p.5). Although I, an individual, am undertaking the research in the spirit of 'teacher-as-researcher' as advocated by Stenhouse (1975) and Whitehead (1985), and 'researcher-as-participator' (Weiskopf and Laske, 1996), colleagues have been, and will be, included throughout the research process. Altricher and Gsettner's (1993) model of action research was adopted as being appropriate for the context. Their four steps of finding a starting point (the number of underachieving students), clarifying the situation (why they might be underachieving), developing action strategies (including PDP processes) and putting them into practice, and publicising the results, allows clarification and putting actions into practice to occur in parallel. This was ethically essential as, to maximise learner development, actions based on findings had to be put into practice when confirmed to increase effectiveness and hence student achievement. 
The research presented in this paper is focused on the 2008/2009 and 2009/2010 cohorts of an education degree. There are two repeated cycles of data collection. The following refers to the first cycle. 157 tutorial records from 56 students submitted with their dissertations were collected. These provided information on the number of tutorials, when they occurred and what was discussed. Therefore I was able to analyse the tutorial records contained as appendices of approximately half of the 106 dissertations submitted. The records were read several times to obtain an overall sense of the content. Brenner et al.'s (1985) approach to content analysis was adopted. Codes were assigned to all utterances in the records according to their perceived meaning. Reliability was maximised by asking a colleague experienced in content analysis to moderate my perceptions. My colleague was provided with samples from the records and the related coded modules of meaning at various points in the process. This resulted in some codes and modules of meaning being amended or amalgamated with others as overlaps were identified. The categories were added to and amended following reflection on the data and the development of interpretations and meanings. They were eventually confirmed as valid by the same colleague involved in verifying the codes. The process was completed by categories being assigned to one of two themes, student-focused issues and supervisorfocused issues. This again was confirmed by the external scrutiny of the colleague involved in the content analysis moderation.

Rich data, subjected to discourse analysis (Parker, 1992), was collected through structured interviews of 6 dissertation students in a focus group and 6 supervisors during the summer term 2009. Also collected for discourse analysis were recordings from three sessions arranged as additional support to the tutorials. Discourse analysis is a generic methodology for analysing the choices of words and actions that members of a group use to engage with each other within and across time, action and activity. Difference between sub-methods can be determined by the type of analysis used. This research adopted the analytic approach advocated by Parker (1992) and Sfard (2001). They use no particular procedure of detailed analysis but look for patterns of language use that can be related to broader themes of social structure and ideological critical evaluation.

The findings from content and discourse analysis were compared with and considered alongside in order to triangulate with quantitative data gathered from student grades, tutorial attendance and tutorial records. The outcomes of the analysed data were disseminated to colleagues in education and to the wider university community during the 
autumn of 2009. Subsequently, recommendations based on the research findings were embedded into final year practice. These included changes to tutorial practice and the organisation of the dissertation module, and to the introduction of a four seminar series at the beginning of the final year to address issues revealed by data analysis.

\section{Analysis, discussion and findings}

\section{The tutorial records and their timings}

It is a requirement of the dissertation process that tutorial records are included as an appendix in the submitted dissertation. Only 56 of the 106 dissertations under analysis contained tutorial records. However, the awarded grades of the sample of 56 dissertations containing tutorial records showed similar distribution to the total number of 106, though the sample showed a slightly higher percentage of A and B awards. A separate record was kept of dates when ethical approval was given. This data was added to that obtained from the tutorial records.

Analysis showed that for all bands but the <D- band (fails), the average number of tutorials attended was three. The first of these tutorials would have been an informal introductory and scoping meeting, leaving an average of two tutorials per student available for supervisors to support the greater part of the dissertation process. For the <D- band, the number of tutorial visits was one. However, as tutorial records of only four students from this group were available for analysis this finding must be taken with caution. Also data from the interview analysis demonstrated that students may have collaborated with their supervisors by e-mail, MSN, telephone or in unrecorded meetings. However, it must be noted from the data available that, as at least one tutorial would have been informal, these students appeared to have had little or no formal/informal support during the rest of their dissertations. Therefore it appears that there is a possibility that some students do not perceive tutorial support as being essential for learning development in relation to their dissertations.

As well as considering the number of tutorials attended by students, data on the time elapsing between tutorials in weeks was analysed. For all grade bands, the longest time was between first and second tutorials, being between 14 and 27 weeks. Subsequent tutorials occurred at more frequent intervals as the date of submission approached, particularly in March and April 2009. These were concerned particularly with data analysis 
and writing up. Discourse analysis indicated that unresolved early difficulties and errors had become embedded in projects. Therefore this research strongly suggests that the time elapsing between first and subsequent tutorials is too long to maximise learner development. Furthermore, I suggest that this mitigates against the establishment of Stefani et al.'s (1997, p.271) '...climate of open dialogue'.

\section{Student-focused issues}

There is clear evidence that students did not realise that a shift of responsibility for learner development from tutors to themselves comes with the dissertation. Supervisor Interview 1 's (Sup/Int.1) comment summarised this perception:

What is different is to the dissertation as a project is that they have to work much more on their own, they have to plan their own time. There is guidance but a lot less of it, in a way, and some find it a lot easier than others.

This is also evidenced by the lack of reading by some students prior to the first tutorial. These students come to the first tutorial with little idea of focus. ' $X$ has very broad ideas about what she wants to do' (Tutorial Record 5: TR 5) and 'brainstormed ideas' (TR 15) are representative of this. Data from the supervisor interviews confirmed this, ' $\ldots$ they don't appreciate how much reading they have to do, particularly through the background' (TR 1), and is representative of all supervisors' perceptions on an overall lack of preparatory reading. Interestingly, there is little difference in the incidence of students not reading, or not reading sufficiently at the time of the first tutorial, across all grade bands. All supervisors shared the view that more able students were able to catch up with the necessary reading during the course of their research but not the $<\mathrm{C}$ - (third class honours and fails) group. A finding of this research is that some form of focused PDP on project management of reading and recording reflective evaluations during the Easter Year 3/October Year 4 period could have been beneficial for learner development, reflecting and extending Harrison and Whalley's (2006) identification of time management as an issue,

The $<\mathrm{C}$ - and $\mathrm{A}-<$ (first class honours) ranges showed a marked difference in the effectiveness of their project management. Project management was identified by combining work needing to be done and the date of the tutorial record. For example, the record of $\mathrm{a}<\mathrm{C}$ - students dated $6^{\text {th }}$ March 2009 (TR 7) reads 'needs to collect the 
research'. Another for the $23^{\text {rd }}$ April states 'first draft of analysis needs to be done'. It must be remembered that the dissertation submission date was $1^{\text {st }}$ May 2009. Significantly, nothing in the tutorial records of the $A-<$ students suggested project management was an issue and there were few incidences in the records of the C- to $\mathrm{C}+$ (thirds) and $\mathrm{B}-$ to $\mathrm{B}+$ (second class honours) ranges. Input on time but not project management was given by the module leader early in the students' fourth year. A finding of this research is that more emphasis should be placed on developing project management skills. It is suggested that more sustained PDP support in this area is necessary, particularly for the potential $<$ Cstudents.

One in five students across all grade bands completed one or more of their tutorial records themselves. TR 13 recorded things to do: 'for next time think about the research in terms of length, audiences for questionnaires etc. and strategies'. TR 11 wrote about how she felt: 'discussion into passion lost with P.E. class....was more confident and focused on changing topics, could list key literature and link to theorists straight away'. These recordings indicate reflection. They do not indicate high quality formative feedback. It could be argued that the tutorial as PDP process should stimulate reflection. It may be that good formative feedback was given verbally during the tutorial but was not recorded. PDP may have been encouraged by e-mail, as part of a telephone conversation or during informal meetings. Analysis has raised the question of the purpose of the tutorial record. It appears to offer not structured, formative support but evidence that tutor and student have met. A finding of this research is that, resonating with Stefani et al's (1997) work, collaborative enhancement of shared understanding and agreement of the purpose and place of the tutorial record is essential to establishing realistic, meaningful PDP to support learner development within the dissertation process.

It was clear from analysis that the sequencing of the dissertation process was an issue for all grade bands apart from $A-<$, reflecting Rowley and Slack's (2006) findings. Analysis suggested that supervisors advised students to begin their empirical research before their literature reviews. This is not effective academic practice as literature reviews inform choice of research questions, methods and analyses. An example is TR 5 whose supervisor writes on the $16^{\text {th }}$ March, six weeks from the submission date, 'future work: draft lit review for consideration by tutor'. This could be connected to the lack of reading prior to the first tutorial noted above. The priority appears to be for students to collect their data, whether or not they have read sufficiently to inform their choice of data collection and 
appropriate methods of analysis. Content analysis suggests that this results in some students having no clear understanding of the sequencing of their research. This could impact on transition between chapters and the embedding of literature in the analysis chapter, issues that were identified in the student interview transcripts as mental blocks. More importantly, it impacts on learner development in understanding rigorous research practice, and deflates and devalues the relevance of the practitioner-as-researcher. This is not desirable at a time when teaching is being promoted as a Masters' profession (DCSF, 2008).

When asked what their mental blocks were, Focus Interviewee 3 (Foc/Int.3) and Foc/Int.5 said in unison 'panic!' to which the other four students in the focus group quickly concurred. 'Panic' in itself is not a mental block but is a state where mental blocks can arise. All students perceived the dissertation as being 'scary' (Foc/Int.3) in being 8,000 words long. These students reported anxiety, confusion and inaction caused by panic which placed them in liminal space. This is a term coined by Meyer and Land (2006) to describe a mental state where students are trapped and unable to proceed with their learning.

Analysis of focus group interview data demonstrated that these students had also personal mental blocks that were inhibiting learner development. Blocks were sometimes experienced by individuals, others were shared. For example, Foc/Int.4 said that for her, data analysis was a mental block: 'I've got lots of stuff from the interviews and children too, but what do I do with it now? The analysis, that's just looking at the results of your data...isn't it?'. She was the only one of the focus group who cited analysis as an issue. However, four of the supervisors reported that they thought that data analysis issues affected dissertation quality. A mental block shared by the whole group was not knowing how to start writing. Foc/Int.1 commented: 'getting started, getting the literature review under way. I've got my research as well. It's just getting started'. Foc/Int.6 provided more detail: 'I don't know where you go, to actually structure your writing. Whenever I've carried out any sort of assignment task I know exactly what I'm doing at each stage, but here there are great areas'.

Other mental blocks identified by the focus group affecting learner development were principally concerned with inability to focus on a realistic research question, to organise the dissertation, to move from one chapter to another, a lack of understanding of the domain 
specific language and difficulties in adopting an academic writing style, issues that resonate with those identified by Rowley and Slack (2006). It is suggested that these can be regarded as threshold concepts because, once they were surmounted, most students passed through Meyer and Land's (2006) portal and accessed the dissertation landscape. Some students got over their mental blocks after collaboration with their tutors, evidence of Stefani et al.'s (1997) 'climate of open dialogue' being established to some degree. As Sup/Int.1 stated:

I like the question about mental blocks because I have some big mental blocks! Just sitting here, doing something like this! So, it yes, students go through the same sort of process, but again, some of them cope with it more than others. I find that, overall, we chat about it on the phone, sometimes even an e-mail, and I give a suggestion, 'Have you thought about...'. It's usually something quite straightforward, it's not complicated, it helps them get over them, over the mental blocks.

Another finding significant in inhibiting learner development was students' perceptions that they had not been given appropriate research skills earlier in the course. This contrasts with the supervisors' perceptions, who maintained that skills had been taught, the issue being that students were not able to transfer their learning into the dissertation, reflecting a finding of Stefani et al.'s (1997, p.271) work. Furthermore, the inference is that students were unable to develop from being given research methods to use in a task by their tutors, to identifying for themselves which methods are applicable to their current research. In other words, they were unable to progress towards the independence and autonomy indicating transformational learning had occurred Mezirow (1997). A finding of this research is that the embedding and progression of research skills in earlier years should be reviewed. However, the interview data suggests that supervisors believe that effective independence is linked to ability, the implicit message being that this is fixed and that little development is possible.

Two other categories of potential issues affecting learner development involved students who attended only one tutorial and students whose focus changed during Year 4. More A$<$ students dropped out of the tutorial system than any other grade band. Any PDP support that they required appears to have been self-generated and addressed either autonomously or collaboratively with the support of their peers. However, supervisors gave mixed responses to the value of peer support. Overall, the supervisors did not see the 
dissertation as being a collaborative activity. Data collection and analysis of students' perceptions on the relative value of tutor and peer support is being included in the second cycle of this research.

Approximately one in ten of the <C- students switched foci. Change of focus resulted from a variety of reasons including boredom, lack of support from schools for the original focus, and student perception that insufficient data would be generated from the original proposal. Two supervisors emphasised the lack of support from schools as an issue influencing the quality of dissertations. A finding of this research is that greater emphasis should be placed on schools supporting dissertation students during school mentor training.

The highest incidence of changing foci came from the $B$ - to $B+$ range with 1 in 5 students changing. One of these students (TR 36) changed her focus in February and achieved B-. So changing focus does not necessarily correlate with a low mark, but could affect students demonstrating their potential. It is suggested that more supervisor support and guidance early in the dissertation might help prevent students choosing inappropriate foci. Greater emphasis on supervisor development per se could be beneficial according to Rowley and Slack's (2006) research.

\section{Supervisor-focused issues}

The principal issue revealed by content analysis affecting learner development was the varying engagement of supervisors with giving feedback and the generally poor quality of formative feedback. Most feedback took the form of recording what had already been done, or procedures to be followed. Examples of such feedback from the tutorial records are 'good progress at this early stage. Identified focus and drafted some key research questions' (TR 18) and 'continue your literature research, speak to school to finalise arrangements for placement and complete proposal ready for next meeting' (TR 9). The amount of feedback given was not indicative of its quality, or the student's eventual achievement. Two <C- students (TR 2 and TR 3) received excellent formative feedback during their first tutorials but did not return for further tutorials. Content analysis revealed that the greatest incidence of poor formative feedback was given to students with grades above A-. Excellent formative feedback was given to a <C- student (TR 14) in three tutorials. With this structured support, a good example of PDP, this student achieved D+. 
Also helpful for learner development were incidences of weakness being identified, for example, the supervisor of TR 5 observed: ' $X$ has struggled to move forward re focus on enquiry'. This category only appeared in the tutorial records of the C-> group.

Supervisors were aware of the issue of differing supervisor input. All mentioned the anxiety this created during their interviews but Sup/Int.4's thoughts most vividly convey the anxiety this created and also a possible solution:

... you think 'Am I doing it right, am I being fair to the others, I just want them to do well'. But we don't talk about how we structure our tutorials. You just do it by habit. But there could be things that I am not asking them to do. And then I have this real worry that some tutors get their students to higher grades, and there's a hierarchy of key tutors. And then I think the students think 'Well I've got uh-uh-uh, never mind, I got so-and-so!' but that really does affect their dissertation, doesn't it? The level of tutoring. So that's my worry.

This supports Rowley and Slack's (2006) assertion that greater supervisor development is needed, a finding of this research. It also raises questions on the extent of supervisors own empirical knowledge of research skills and methods. The two supervisors interviewed who had recently completed their Masters, which included both literature review and empirical research, both commented on how much this learning experience and assignment outcomes had impacted on their practice.

\section{Conclusion}

The tutorial as used in the final year of the education course chosen as this research focus appears to be effective as a PDP process enabling learner development in meeting the needs of some students but not all, particularly the lower achieving students. Additionally, this research indicates that not all learners perceive tutorial support as being essential for the development necessary for successful completion of their dissertations. A major factor appears to be the lack of engagement of students with preliminary reading, resulting in students not being prepared for their first tutorial during which their ethics proposal form, containing their research design outline, is discussed. Furthermore, the time elapsing between first and subsequent tutorials is too long. More organised, knowledgeable 
students appear to be able to cope and catch up; others cannot. Taking into account that students have other assignments, school experience to complete and personal and social issues to deal with during the dissertation period, the ability to manage their dissertation is of crucial importance. Although time management is taught during the dissertation period, this research has demonstrated that more emphasis needs to be placed on project management. Ideally project management skills should be initiated in Year 1 and developed in subsequent years.

The dissertation is seen as an activity that demonstrates and encourages student independence and autonomy. This suggests that students need to be aware of the skills, particularly research skills they have already gained so that they can draw on them to support the making of informed choices on appropriate methodologies. This research has highlighted the fact that some students are unable to transfer the research skills they have obtained through tasks in earlier years to the dissertation. Learner development is inhibited as this inability encourages the formation of mental blocks and throws students into Meyer and Land's (2006) liminal space. Their motivation to act independently is affected. As a consequence their tutorial time is not used effectively to develop collaborative learning. Also, analysis suggests that some students are not secure in their knowledge of research methods and analysis techniques, particularly qualitative analysis.

It is suggested that learner development could be enhanced through supervisor development. The university's research communities of practice would be appropriate fora for this, being directed at encouraging and supporting activities to promote enquiry and evidence based pedagogies. It is proposed such pedagogies should include resources and activities, possibly hosted on e-Portfolio software, related to the practice of and reflection on research skills acquired over the four years of the degree. These records and reflections would be a useful resource for informing methodological choices for the dissertation and as bases for discussion at tutorials. A finding of the research is that both supervisors and students regarded the dissertations a solitary activity, despite the fact that the tutorial is a collaborative practice. It is also evident that students talked with each other. Therefore, it is proposed that effective supervisor and learner development could include encouragement of the use of wikis, blogs, e-mail, discussion fora within learning platforms, social networking websites, MSN and the telephone/mobile as collaboration tools, as well as the tutorial, to extend the range of means of peer, student-supervisor and supervisor-supervisor support. 
The number of students who complete their own tutorial records has called into question the purpose of the tutorial record and quality of supervision. Whether the tutorial record is to be the principal vehicle of formative feedback completed by the supervisor, or to be a record of student reflection attracting credit, it needs to be of an agreed and shared standard and fit for purpose. This process could lead into activities with students that precede the tutorials, the aim being to match and build relationships between supervisor and students within a 'climate of open dialogue' to facilitate learner development.

The design of the undergraduate dissertation demands that ensuring effective learner development is a responsibility of both student and supervisor, reflecting autonomous (Mezirow, 1999) and collaborative (Vygotsky, 1987) learning mediated through the tutorial. This research clearly demonstrates that for effective learner development for the dissertation, review was needed of its content and organisation, of the tutorial processes within it, and of the responsibilities of supervisor and student in their engagement. Following the completion of the first cycle, some changes were made. The content of the module was increased in that four introductory sessions were timetabled at the beginning of the final year. These focused on revising ethics, research methods, searching for appropriate literature, dissertation structure and sequencing of its various parts. No changes were made to the tutorial itself, though students were encouraged to meet their supervisors on a monthly basis. Supervisors were advised that they must complete the tutorial records themselves and give detailed feedback. However, no supervisor development was organised, neither has any guidance or support been given on establishing collaboration outside the tutorial, face-to-face or online. It is too early to be able to provide findings of the second cycle. The research reported here is small-scale and is not yet complete. At the moment its findings can only be applied with confidence to the cohort researched. The purpose of analysing the second cycle of data is to identify specific PDP interventions for supervisor and student consideration, aimed at improving learner development during the dissertation process.

\section{Acknowledgement}

This paper is an outcome of the National Action Research Network on researching and evaluating Personal Development Planning and e-Portfolio practice project (2007-2010). The project was led by the University of Bolton in association with the University of 
Worcester and Centre for Recording Achievement, and in national collaboration with the University of Bedfordshire, Bournemouth University and University of Bradford. The project was funded by the Higher Education Academy, National Teaching Fellowship Project strand. More details about the project can be found at: http://www.recordingachievement.org/research/narn-tree.html.

\section{References}

Altricher, H. and Gsettner, P. (1993) 'Action research: a closed chapter in the history of German social science?', Educational Action Research, 1(3), pp. 329-360.

Atlay, M. T. (2007) 'Embedding PDP practice in the Curriculum', in Centre for Recording Achievement: Personal Development Planning and Employability. York: Higher Education Academy.

Atlay, M.T., Petrova, P. and Ujma, D. (2009) To embed or not to embed? The embedding of PDP in the curriculum. Available at:

http://www.heacademy.ac.uk/assets/hlst/documents/case studies/ujma.pdf (Accessed: 14 September 2009).

Biggs, J. and Tang, C. (2007) Teaching for quality learning at university. $3^{\text {rd }}$ edn. Buckingham: Open University Press.

Brennan, J. and Shah, T. (2003) Report on the implementation of Progress Files. http://oro.open.ac.uk/324/1/ProgressFiles.pdf (Accessed: 21 September 2010).

Brenner, M., Brown, J. and Canter, D. (eds.) (1985) The research interview: uses and approaches. London: Academic Press.

Buckley, C. (2007) 'Walking the PDP line: negotiating connections and boundaries in Higher Education', On Reflection, 14, pp. 4-6. 
Bush, H. and Bissell, V. (2008) 'The evaluation of an approach to reflective learning in the undergraduate dental curriculum, European Journal of Dental Education, 12, pp.103-110.

Clegg, S. and Bradley, S. (2006) 'The implementation of progress files in higher education: reflection as national policy', Higher Education, 51, pp. 465-486.

Department for Children, Schools and Families (2008) New Masters qualification to boost teaching. Available at: http://www.dcsf.gov.uk/pns/DisplayPN.cgi?pn id=2008 0044 (Accessed: 3 July 2010).

Elliott, J. (1991) Action research for educational change. Buckingham: Open University Press.

Habermas, J. (1984) The theory of communicative action. Vol. 1: reason and the rationalisation of society. Translated by T. McCarthy. Boston: Beacon Press.

Hammick, M. and Acker, S. (1998) 'Undergraduate research supervision: a gender analysis', Studies in Higher Education, 23(3), pp. 335 - 347.

Harrison, M.E. and Whalley, W.B. (2006) Combining student independent learning and peer advice to improve the quality of undergraduate dissertations. Available at: http://www.gees.ac.uk/planet/p16/mh.pdf (Accessed: 31 August 2009).

Higher Education Academy (2009) Personal Development Planning. Available at: http://www.heacademy.ac.uk/ourwork/learning/pdp (Accessed: 26 February 2009).

Kemmis, S. and McTaggart, R. (eds.) (1992) The action research planner. $3^{\text {rd }}$ edn). Geelong, Victoria, Australia: Deakin University Press.

Kumar, A. (2008) Personal, academic and career development in higher education. London: Routledge.

Meyer, J. and Land, R. (eds.) (2006) Overcoming barriers to student understanding. London: Routledge. 
Mezirow, J. (1997) 'Transformative learning: from theory to practice', New Directions for Adult and Continuing Education, 74, pp. 5-12.

National Action Research Network (2007) Researching and evaluating Personal Development Planning (PDP) and e-Portfolio. Available at: http://www.recordingachievement.org/research/narn-tree.html (Accessed: 11 May 2010).

Parker, I. (1992) Discourse dynamics: critical analysis for social and individual psychology. London: Routledge.

Rowley, J. and Slack, F. (2006) What is the future for undergraduate dissertations? http://digitalcommons.shu.ac.uk/cgi/viewcontent.cgi?article=1003\&context=ccrc pa pers (Accessed: 11 September 2009).

QAA (2001) Guidelines for HE progress files. Available at: www.qaa.ac.uk/academicinfrastructure/progressfiles/guidelines/progfile2001.pdf (Accessed: 1 April 2009).

Sfard, A. (2001) 'There is more to discourse than meets the ears: learning from mathematical things we have not known before', Education Studies in Mathematics, 46(1/3), pp. 13-57.

Stefani, L.A.J., Tariq, V-N., Heylings, D.J.A. and Butcher, C. (1997) 'A comparison of tutor and student conceptions of undergraduate research project work', Assessment and Evaluation in Higher Education, 22(3), pp. 271 - 288.

Stefani, L., Mason, R. and Pegler, C. (2007) The educational potential of e-Portfolios. London: Routledge.

Stenhouse, L. (1975) An introduction to curriculum research and development. London: Heinemann.

Vygotsky, L.S. (1978). Mind in society: development of higher psychological processes. Harvard MA: Harvard University Press. 
Weiskopf, R. and Laske, S. (1996) 'Emancipatory action research: a critical alternative to personal development or a new way of patronising people?', in Zuber-Skerritt, O. (ed.) New directions in action research. London: Falmer, pp. 173-182.

Whitehead, J. (1985) 'An analysis of an individual's educational development: the basis for personally orientated action research', in Shipman, M. (ed.) Educational research: principles, policies and practices. Lewes: Falmer, pp. 97-108.

Zuber-Skerritt, O. (1996) 'Introduction', in Zuber-Skerritt, O. (ed.) New directions in action research. London: Falmer, pp. 3-9.

\section{Author details}

Dr Andrea Raiker is based in the Directorate of Teaching and Learning at the University of Bedfordshire where she works on curriculum development. Her research interests are focused on the exploration of processes affecting student achievement, in particular, the role of language and technology in these processes. 